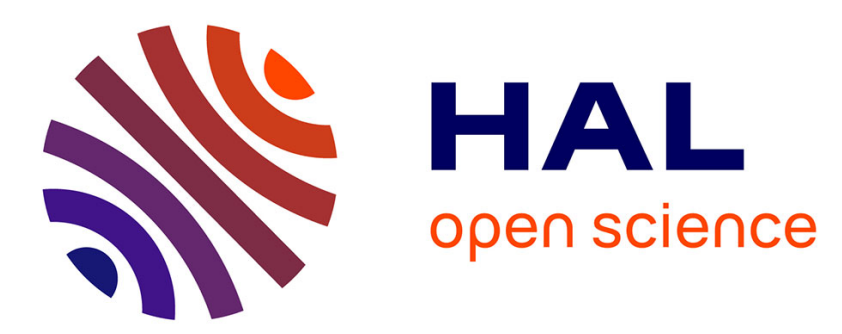

\title{
An experimental study of competition between fire ants and Argentine ants in their native Range
}

E. G. Lebrun, C. V. Tillberg, A. V. Suarez, P. J. Folgarait, C. R. Smith, D. A. Holway

\section{- To cite this version:}

E. G. Lebrun, C. V. Tillberg, A. V. Suarez, P. J. Folgarait, C. R. Smith, et al.. An experimental study of competition between fire ants and Argentine ants in their native Range. Ecology, 2007, 88 (1), pp.63-75. 10.1890/0012-9658(2007)88[63:aesocb]2.0.co;2 . hal-01589575

\section{HAL Id: hal-01589575 \\ https://hal.science/hal-01589575}

Submitted on 18 Sep 2017

HAL is a multi-disciplinary open access archive for the deposit and dissemination of scientific research documents, whether they are published or not. The documents may come from teaching and research institutions in France or abroad, or from public or private research centers.
L'archive ouverte pluridisciplinaire HAL, est destinée au dépôt et à la diffusion de documents scientifiques de niveau recherche, publiés ou non, émanant des établissements d'enseignement et de recherche français ou étrangers, des laboratoires publics ou privés. 


\title{
AN EXPERIMENTAL STUDY OF COMPETITION BETWEEN FIRE ANTS AND ARGENTINE ANTS IN THEIR NATIVE RANGE
}

\author{
E. G. LeBrun, ${ }^{1,4}$ C. V. Tillberg, ${ }^{2}$ A. V. Suarez, ${ }^{2}$ P. J. Folgarait, ${ }^{3}$ C. R. Smith, ${ }^{2}$ and D. A. Holway ${ }^{1}$ \\ ${ }^{1}$ Division of Biological Sciences, University of California at San Diego, La Jolla, California 92093 USA \\ ${ }^{2}$ Department of Entomology and Department of Animal Biology, University of Illinois, Urbana, Illinois 61801 USA \\ ${ }^{3}$ Programa de Investigación en Interacciones Biológicas, Centro de Estudios e Investigaciones, Universidad Nacional de Quilmes, \\ Buenos Aires B1876BXD, Argentina
}

\begin{abstract}
An understanding of why introduced species achieve ecological success in novel environments often requires information about the factors that limit the abundance of these taxa in their native ranges. Although numerous recent studies have evaluated the importance of natural enemies in this context, relatively few have examined how ecological success may result from differences in the magnitude of interference competition between communities in the native and introduced ranges of nonnative species. Here we examine how native-range competitive environments may relate to invasion success for two important invasive species, the red imported fire ant (Solenopsis invicta) and the Argentine ant (Linepithema humile), in a region of native-range sympatry. At two study sites in northern Argentina, we used stableisotope analysis, a variety of observational approaches, and two different reciprocal removal experiments to test (1) whether $S$. invicta competes asymmetrically with L. humile (as suggested by the 20th century pattern of replacement in the southeastern United States) and (2) the extent to which these two species achieve behavioral and numerical dominance. Stable-isotope analysis and activity surveys indicated that S. invicta and L. humile are both omnivores and forage during broadly overlapping portions of the diel cycle. Short-term removal experiments at baits revealed no competitive asymmetry between $S$. invicta and L. humile. Longer-term colony removal experiments illustrated that $S$. invicta and $L$. humile experience an approximately equal competitive release upon removal of the other. Our results indicate that neither $S$. invicta nor $L$. humile achieves the same degree of behavioral or ecological dominance where they co-occur in native populations as they do in areas where either is common in their introduced range. These results strongly suggest that interspecific competition is an important limiting factor for both S. invicta and L. humile in South America.

Key words: Argentina; Argentine ant; competition; fire ant; invasion; Linepithema humile; removal experiment; Solenopsis invicta.
\end{abstract}

\section{INTRODUCTION}

Although research on biological invasions has grown enormously since Elton's (1958) seminal synthesis, most work in this field remains exclusively focused on introduced populations. This introduced-range bias may limit an understanding of the general causes of invasion success. Research on populations of invasive species in their native ranges, for example, can reveal important differences between native and introduced populations (e.g., in the prevalence of polygyny [Ross et al. 1996], in the relative genetic diversities of populations and the prevalence of intraspecific aggression [Tsutsui et al. 2000], or in the resistance of competitors to allelopathic chemicals [Callaway and Aschehoug

Manuscript received 31 December 2005; revised 31 May 2006; accepted 5 June 2006. Corresponding Editor: M. D. Eubanks.

${ }^{4}$ Present address: University of Texas at Austin, Brackenridge Field Laboratory, 2907 Lake Austin Boulevard, Austin, Texas 78703 USA. E-mail: elebrun@mail.utexas.edu
2000]). These differences can provide surprising insights into the success of introductions (Wolfe 2002).

The ecological and evolutionary histories of introduced species influence their ability to spread into new environments in numerous ways. Ecological success, for example, may result from nonnative species escaping their predators, parasites, or pathogens (Mitchell and Power 2003, Torchin et al. 2003). The importance of enemies in this context is underscored by their key role in biological control (De Bach 1974). Interspecific competition, by comparison, has received less attention with respect to invasion success, especially for animal introductions. Disparities in the magnitude of interspecific competition between communities in the native and the introduced ranges of nonnative species may nonetheless contribute importantly to ecological success in new environments (Vermeij 1991, Tilman 1999, Callaway and Aschehoug 2000). If the competitive environments of donor communities are more intense than those of recipient communities, for example, then an invader's competitive ability should more closely resemble species 
from its native range than species from its introduced range (Tilman 1999).

In this study we examine how native-range competitive environments may relate to invasion success for two widespread, abundant, and ecologically damaging invasive species: the Argentine ant (Linepithema humile) and the red imported fire ant (Solenopsis invicta). Our focus is novel in that we address the nature of interspecific competition between two invasive species in a region of extensive native-range sympatry. Although it is recognized that $S$. invicta and L. humile originate from the same general region of South America, our recent surveys reveal that these two ants frequently co-occur in floodplain woodlands along the major rivers of northern Argentina. Solenopsis invicta occurs from the vicinity of Rosario, Argentina, north along the Río Paraná to its confluence with the Río Paraguay and from there north in the drainage of the Río Paraguay into Paraguay and southern Brazil (Buren et al. 1974, Ross and Trager 1990, Mescher et al. 2003). The native range of $L$. humile overlaps the southern portion of the red imported fire ant's range and is centered on the Río Paraguay and the lower Río Paraná drainages of northern Argentina and surrounding regions (Tsutsui et al. 2001, Wild 2004) (see Appendix A).

Despite the large number of published studies on $S$. invicta and L. humile, remarkably little information exists concerning interactions between the two species. Several decades after L. humile was first recorded in the United States (in 1891), it had spread throughout the Southeast (Suarez et al. 2001). Introductions of $S$. invicta (and S. richteri) followed the arrival of $L$. humile in this region, and these fire ants (especially $S$. invicta) spread quickly and apparently at the expense of the Argentine ant. Although imported fire ants appear to have displaced Argentine ants from the southeastern United States, supportive evidence is largely anecdotal. In roadside surveys conducted near Mobile, Alabama, for example, Glancey et al. (1976) found S. invicta common in areas that were previously dominated by $L$. humile. Likewise, Buren et al. (1974) state that S. invicta replaced L. humile in New Orleans, Louisiana, a location where Argentine ants were considered a pest in the early 1900s. Wilson (1951) speculated that L. humile might hold its own in urban areas but lose ground to Solenopsis in more open environments. The currently patchy and largely urban distribution of $L$. humile in the southeast (e.g., Buczkowski et al. 2004) fits Wilson's conjecture.

Unlike the situation in North America, in South America, S. invicta and L. humile occur in species-rich communities of ants (Allen et al. 1974, Suarez et al. 1999) and often coexist. The presumed intensity of interspecific competition in these communities may contribute to the success of $L$. humile and $S$. invicta introductions (Feener 2000). Consistent with this hypothesis are studies documenting that introduced populations of $S$. invicta and L. humile exceed native ants in how quickly they discover food and in how effectively they usurp food from competitors (Porter and Savignano 1990, Human and Gordon 1996, Holway 1999, Morrison 2000). Little is known about the competitive rankings of $S$. invicta and $L$. humile in South American ant communities, however.

Here we examine the dynamics of interspecific competition in omnivorous ant communities from South America that include both S. invicta and L. humile. We use stable-isotope analysis, a variety of observational approaches, and two types of reciprocal removal experiments to test the following hypotheses. First, given the historical pattern of displacement in the southeastern United States, we predict that, in South America, S. invicta competes with L. humile in an asymmetrical manner, with fire ants acting as the behavioral dominant. Second, as a result of presumed differences in the competitive environments of North and South America, we predict that neither $S$. invicta nor L. humile achieve the extreme levels of behavioral or numerical dominance observed in their introduced ranges. Given the unique focus of this study, our results provide a novel and informative measure of the manner in which geographical disparities in competitive environments may contribute to success of animal invasions. Moreover, an improved understanding of the manner in which $S$. invicta and L. humile interact with one another seems warranted given the prominence of these species as invaders and the likelihood that the extent of their introduced range sympatry will increase over time as a result of the unfortunate, but perhaps inevitable, range expansions anticipated for both species (Morrison et al. 2004, Roura-Pascual et al. 2004).

\section{Methods}

Study sites

We conducted research at two sites in northern Argentina: (1) Ocampo $\left(28^{\circ} 29^{\prime} \mathrm{S}, 59^{\circ} 16^{\prime} \mathrm{W}\right), 6 \mathrm{~km}$ east of the town of Villa Ocampo (Santa Fe Province) in the floodplain of the Rio Paraná, and (2) Herradura (26 $31^{\prime}$ $\left.\mathrm{S}, 58^{\circ} 17^{\prime} \mathrm{W}\right), 5 \mathrm{~km}$ east of the town of Herradura (Formosa Province) and along Rio Paraguay. Fieldwork took place during November-December 2003 and November-December 2004. The two sites, separated by $\sim 300 \mathrm{~km}$, are in the Chaqueña phytogeographical province.

Ocampo receives an average of $124 \mathrm{~cm}$ of rain a year (data from Reconquista, Argentina [80 km to the south of Villa Ocampo]). We worked in open savanna habitats that had scattered Acacia trees and small stands of dense subtropical forest (see Plate 1). Herradura receives an average of $139 \mathrm{~cm}$ of rain per year (data from Formosa, Argentina [40 $\mathrm{km}$ to the north of Herradura]). We worked in and adjacent to a riverside park maintained for camping and fishing. Subtropical forest and wetlands surround this site. Although a modified habitat, this site supports a diverse ground-foraging ant community with 


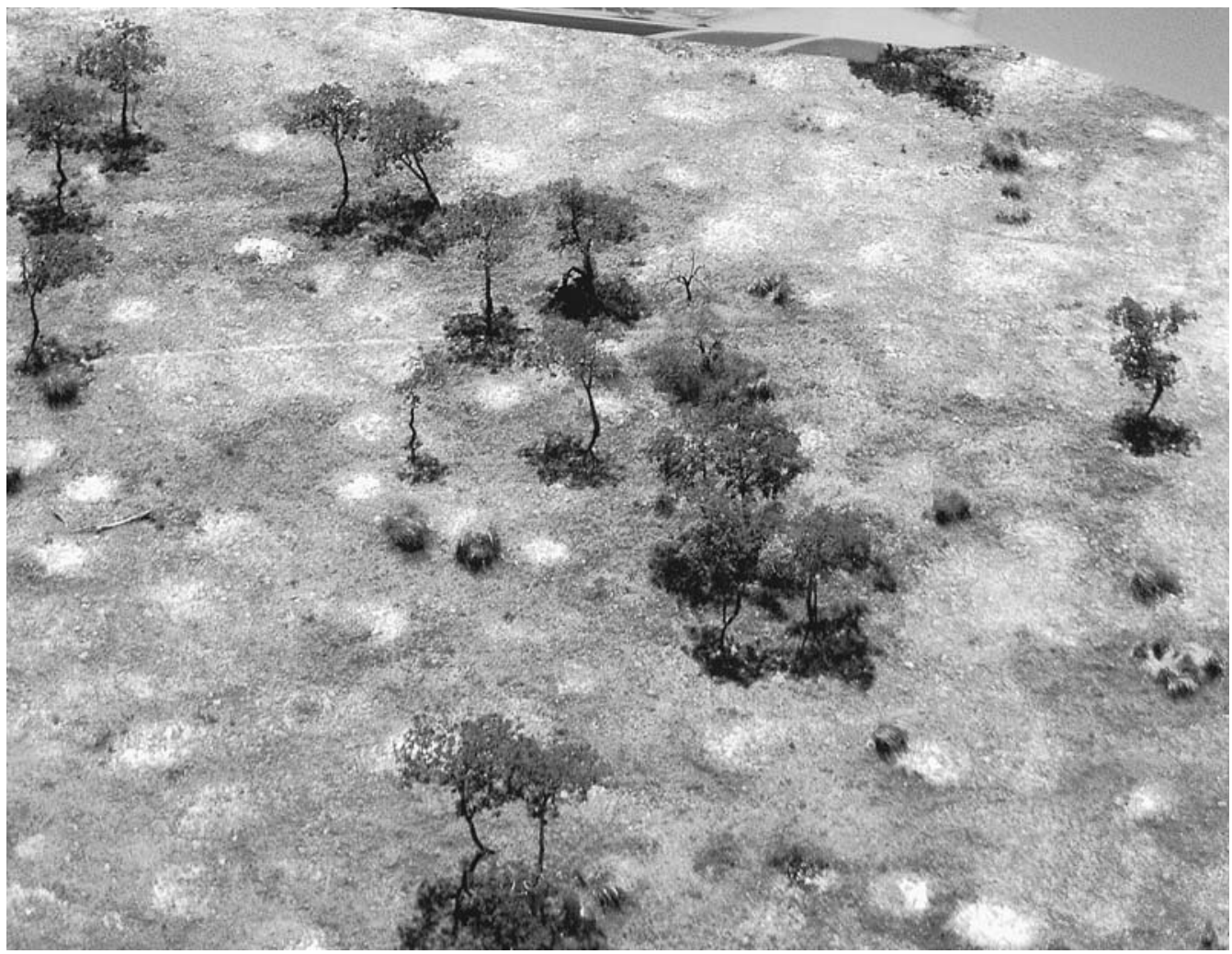

Plate 1. An aerial photo of the field site near Villa Ocampo, Argentina. The white circles of bare soil, $\sim 1$ meter in diameter, are adjacent to active and abandoned ant nest mounds constructed primarily by Solenopsis invicta with a lesser number constructed by Camponotus punctulatus. The mounds are often secondarily occupied by Linepithema humile and S. (Diplorhoptrum) sp. This area was the site of one of the plots in the colony removal experiment. Photo credit: C. R. Smith.

high densities of S. invicta and L. humile. Both Ocampo and Herradura can become extensively flooded during the wet season. We replicated all work at both sites except for the colony removal experiment (performed only at Ocampo).

\section{Species}

Both of the study sites fall within the native ranges of L. humile and S. invicta (Pitts 2002, Wild 2004) (see Appendix A). No other species of Linepithema is common in this part of Argentina (Wild 2004). The only other member of the Solenopsis saevissima species group that occurs in this area (S. macdonaghi) is easily differentiated from $S$. invicta based on morphology (Pitts 2002) and did not occur at either study site. Our sites are near areas known to contain polygyne $S$. invicta (Mescher et al. 2003). However, populations of S. invicta at both sites were apparently comprised of monogyne colonies. Extensive nest excavations never revealed more than one queen per colony.

At both sites we define the community of competitors that interact with $S$. invicta and L. humile as those ant species observed foraging at baits in the morning and evening, the periods when $S$. invicta and L. humile are most active in the austral spring. Voucher specimens are deposited at the Bohart Museum of Entomology, University of California at Davis (UCDC), the University of Illinois, and the Natural History Museum Bernardino Rivadavia in Buenos Aires.

\section{Stable-isotope analysis}

To infer the relative trophic positions of L. humile and $S$. invicta, we analyzed stable isotopes of carbon and nitrogen from field-collected workers. Nitrogen isotopes can clarify the relative trophic positions of species in food webs. Over a broad range of taxa, for example, 2 $3 \%$ enrichment in nitrogen isotopes typically separates trophic levels (Deniro and Epstein 1981, Post 2002, McCutchan et al. 2003, Vanderklift and Ponsard 2003). Carbon isotopic values of consumers reflect the photosynthetic pathway $\left(\mathrm{C}_{3}\right.$ or $\left.\mathrm{C}_{4}\right)$ by which the carbon was fixed in plant forage (Lajtha and Michener 1994).

At each site, we collected workers from at least 10 colonies of both L. humile and S. invicta and from 1-5 colonies of other common ant species. Samples were frozen within $1 \mathrm{~h}$ of collection, dried in an oven at $60^{\circ} \mathrm{C}$ for two days, and stored with desiccant until processing. Each sample consisted of the head, thorax, and legs (after Tillberg et al. 2006) of 10-15 workers from one colony such that the sample mass summed to $\sim 1500 \mu \mathrm{g}$. 
Samples were analyzed at the University of California Davis Stable Isotope Facility. The standard for carbon analysis was PeeDee Belemnite carbonate; atmospheric air was the standard for nitrogen analysis.

At each site, we compared $\delta^{15} \mathrm{~N}$ and $\delta^{13} \mathrm{C}$ between $L$. humile and $S$. invicta using a MANOVA to test for an overall difference, followed by two one-way ANOVAs to detect the source of the difference $\left(\delta^{15} \mathrm{~N}\right.$ or $\left.\delta^{13} \mathrm{C}\right)$, if one was present. To control family-wide error rate, the $P$ values for the one-way ANOVAs were adjusted according to the sequential Bonferroni procedure. The relative trophic position of other ant species was categorized based on their foraging ecology. High-trophic-position ants include army ants in the genera Labidus and Neivamyrmex, the ponerimorph genera Ectatomma, and Pachycondyla, and the genus Forelius. Low-trophicposition ants included species that rely heavily on plant material, honeydew, extrafloral nectar, or fungus (genera Acromyrmex, Cephalotes, Cyphomyrmex, Nesomyrmex, and Myrmelachista). Ants with omnivorous diets and intermediate $\delta^{15} \mathrm{~N}$ values were from a wide variety of genera including Azteca, Brachymyrmex, Crematogaster, Dorymyrmex, Paratrechina, Pogonomyrmex, Pseudomyrmex, and Solenopsis (subgenus Diplorhoptrum).

\section{Activity profiles}

To quantify temporal patterns of foraging activity for $S$. invicta and L. humile, we established $101-\mathrm{m}^{2}$ plots at each site in areas where we observed $L$. humile and $S$. invicta on the ground within $0.5 \mathrm{~m}$ of one another. We sampled plots every $4 \mathrm{~h}$ over $24 \mathrm{~h}$ by collecting all ants detected within each plot during 5-min sampling periods. Plots were separated by at least $50 \mathrm{~m}$.

\section{Short-term removal experiment}

In 2003 and 2004, we conducted competitor removal experiments to test the degree to which $L$. humile and $S$. invicta differ in competitive dominance. These experiments compare the ability of the two species to capture food in each other's presence (control) with their ability to capture food when their main competitor (i.e., $L$. humile or S. invicta) is excluded (treatment). At each study site, we established bait stations (Ocampo, $N=23$; Herradura, $N=16$ ) that were at least $25 \mathrm{~m}$ apart and were situated in areas where L. humile and $S$. invicta foraged within $\sim 0.5 \mathrm{~m}$ of one another. At each station we placed $2 \mathrm{~g}$ of tuna in oil at the center of circular laminated cards $(24 \mathrm{~cm}$ in diameter). Tuna baits are often used in studies of omnivorous ant communities to simulate large persistent food items. This type of bait represents a particularly relevant resource at our study sites because ants often scavenge stranded aquatic organisms (e.g., fish, snails). Control and treatment trials were conducted at the same time of day over three consecutive days. We performed controls on the first day to prevent treatment manipulations from influencing the outcome of controls, but the order of removal trials was always randomized. In the treatments we aspirated all $L$. humile or S. invicta workers that approached the bait station and then released them $>1 \mathrm{~m}$ away from the station. At each station, we monitored all ants until 60 min after a species had recruited at least 10 workers. Stations at which multiple species contested baits at the end of $60 \mathrm{~min}$ were monitored until only one species remained. We recorded the identity and number of all ants present and, at the end of each trial, vouchered all species observed. In 2004, upon completion of the final removal trial, we set four pitfall traps at $90^{\circ}$ angles, $2 \mathrm{~m}$ from each bait station. Traps provide a measure of local forager density. Pitfall traps were installed using a pipe to remove a soil plug exactly the size of the trap. This method minimizes soil disturbance. Prior to all sampling, we left pitfall traps, 50-mL centrifuge tubes with a $3 \mathrm{~cm}$ diameter opening, closed for $48 \mathrm{~h}$ to eliminate any digging-in effects. Traps were charged with a solution of water, odorless detergent, and salt and remained open for $48 \mathrm{~h}$.

We analyzed data for the short-term removal experiments as follows. We used chi-square goodness-of-fit tests to evaluate whether reciprocal removal of $L$. humile or $S$. invicta enhanced the ability of the unremoved focal species to monopolize resources. In this analysis the outcomes of control trials were used as the expected values. To test for any competitive asymmetry between L. humile and S. invicta, we evaluated the significance of the three-way interaction term from a log-linear model describing the interaction of species identity ( $L$. humile or $S$. invicta) by treatment (competitor present or absent) by outcome (bait won or lost). A significant interaction indicates the existence of a competitive asymmetry. We also used log-linear analysis to test for between-site differences in the responses of L. humile and $S$. invicta. We used logistic regression to determine whether the outcome of control trials resulted from differences in relative local worker density between $L$. humile and $S$. invicta. Relative local worker density was estimated by subtracting the mean number of $S$. invicta workers in pitfall traps from that location (i.e., bait station) from the mean number of L. humile workers in those same traps. We evaluated the significance of worker density by comparing the fit of the full model to the fit of the model that excluded the predictor variable term. For sample sizes $<50$, this approach behaves more reliably compared to explicit tests of the parameter estimate (Quinn and Keough 2002).

\section{Colony removal experiment}

Because the removal experiments described above capture short-term and small-scale aspects of competition between L. humile and S. invicta, we also performed a longer-term and larger-scale reciprocal colony removal experiment to test whether the two species undergo different levels of ecological release upon removal of competing colonies. We performed this experiment at Ocampo where we established 22 plots $(10 \times 10 \mathrm{~m})$ in 
open savanna habitat in 2004. Plots were separated by at least $50 \mathrm{~m}$, and the complete array spanned $20 \mathrm{ha}$. We selected plot locations by searching for areas where $L$. humile and $S$. invicta foraged together within $1 \mathrm{~m}$ of one another. The center of each plot was then set at the midpoint between the $S$. invicta mound nearest the location where we observed the two species together and the nearest large L. humile nest. In each plot we established a square grid of 16 equally spaced bait stations and installed pitfall traps at the plot center and at each corner. Trapping methods were the same as in the short-term removal experiment. Each plot was assigned to one of three experimental groups: control $(N=9)$, L. humile removal $(N=6)$, or $S$. invicta removal $(N=7)$. We assigned treatments to plots in order to maximize the degree of spatial interspersion among experimental groups.

To remove colonies of $S$. invicta and L. humile, we used boiling water and localized soil excavation. Although more labor-intensive than using pesticides, this approach minimizes nontarget effects. Superficial $L$. humile nests, those at the base of trees or in grass tussocks, were treated with boiling water alone. We attempted to remove all nests of the focal species inside each treatment plot and within a surrounding 10-m buffer zone. This buffer size is sufficient to prevent the foraging territories of adjacent fire ant colonies from overlapping the plot (Tschinkel et al. 1995). In order to assure that $L$. humile removal plots would not be recolonized by this somewhat nomadic species, concentrations of L. humile workers were removed from an additional 5-m buffer area. Solenopsis invicta removals required the elimination of $1.9 \pm 1.2$ (mean $\pm \mathrm{SD}$ ) colonies inside the plot and an additional $4.6 \pm 3.2$ in the buffer zone, while L. humile removals required the removal of $2.8 \pm 2.1$ ground nests in the plot and an additional $4.7 \pm 4.5$ ground nests in the buffer zone. Additional nests of $L$. humile removed from trees and grass tussocks required no soil disturbance. To mimic soil disturbances inherent in colony removals, we shamtreated control plots by excavating and pouring boiling water onto 5-9 randomly chosen locations (each $0.5 \times$ $0.5 \mathrm{~m}$ ) within these plots or their buffer zones that did not contain obvious ant nests. We matched the number of sham disturbances in controls to the amount of soil disturbance required to remove focal competitors from adjacent removal plots.

We sampled all plots prior to colony removals and then 12-18 days after treatment. Sampling consisted of baiting and pitfall trapping. To bait each plot, we placed tuna baits on $7 \times 7 \mathrm{~cm}$ laminated cards at each of the 16 stations in the plot. At 30 and $90 \mathrm{~min}$ after bait placement (at 07:30), we identified and counted all ants at the stations. Species that were in sole control of baits at $90 \mathrm{~min}$ were considered winners. Baits were removed, and a minimum of $4 \mathrm{~h}$ after baiting, during the early afternoon when ground temperatures were too hot to allow any of the species active in the morning to forage, we returned and opened the pitfall traps.

We quantified spatial overlap in the foraging ranges of L. humile and $S$. invicta using the corner pitfall traps from the pre-manipulation sample of the colony removal plots. The presence/absence data from these traps were analyzed using the co-occurrence platform in EcoSim (Gotelli and Entsminger 2004). For this analysis, $S$. invicta or L. humile were scored as "present" only if traps contained a median number of workers or more for that species. Thus the analysis evaluated whether $S$. invicta and L. humile were positively, negatively, or randomly associated at locations where their workers were common. Row totals in the random matrices were fixed, but column totals were free to vary. The program uses the $c$-score statistic to compare the observed level of co-occurrence with the distribution of random matrices to determine the probability of observing that level of co-occurrence by chance (Stone and Roberts 1990, Gotelli 2000).

We quantified the degree of competitive release exhibited by L. humile and S. invicta as follows. For each plot, we calculated the fraction of bait stations controlled by either L. humile or S. invicta in the final sampling period that were controlled by the opposite competitor in the initial sampling period. For L. humile and $S$. invicta separately, we then used two-sample $t$ tests to compare these proportions between control and treatment plots. In order to improve normality, these proportions were arcsine square-root transformed prior to analysis (Sokal and Rohlf 2000). In one control plot, a colony of the behaviorally dominant Crematogaster quadriformis was inactive during the initial sampling period but captured a majority of the baits in the final sampling period. Because this did not occur in any removal plot, we eliminated this plot from the analysis. Another control plot was identified by its studentized residual as an outlier (Quinn and Keough 2002) and was similarly excluded. In this plot $S$. invicta captured a single bait station in the initial sampling period, but $L$. humile captured this station in the final sampling period.

We used pre-removal baiting data from our 22 experimental plots to generate a behavioral dominance hierarchy for the Ocampo ant community. To assemble this hierarchy, we collated 84 observations of turnovers (cases in which one species displaced another from a bait) for the eight most common species at baits on our plots. Turnover data for rare species were too scarce $(\leq 4$ interactions per species) to resolve their relative behavioral dominance. We considered a species to be in control of a bait when it had recruited 10 or more workers and when no other species had more than three workers present. To construct this dominance hierarchy, we first entered the total number of wins and losses observed for every possible species pair into a twodimensional matrix. A species won an interaction if it replaced a species that had previously controlled the resource. Species were arranged so as to minimize the 


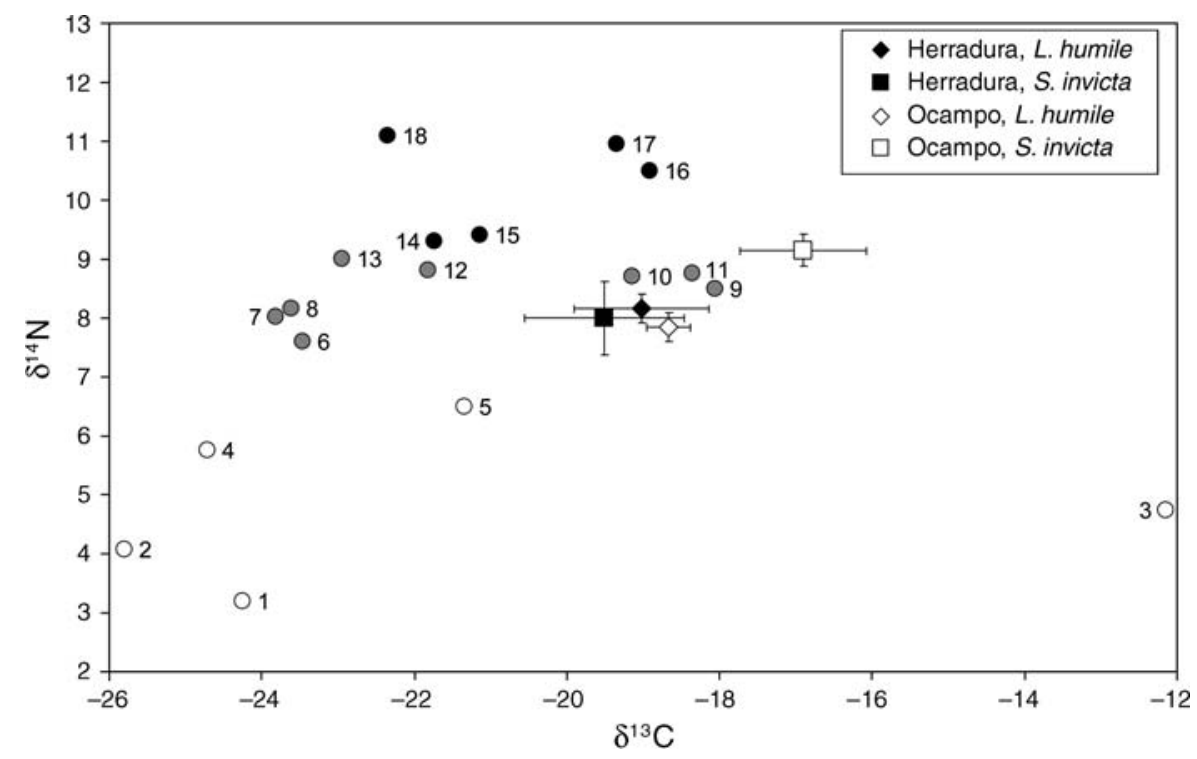

FIG. 1. Stable isotope values (means $\pm \mathrm{SE}$ ) for carbon and nitrogen for Solenopsis invicta and Linepithema humile at Ocampo and Herradura in northern Argentina within the context of the entire ant community. Numbered circles represent mean $\delta^{15} \mathrm{~N}$ and $\delta^{13} \mathrm{C}$ values for ants with plant-based (honeydew, nectar, extrafloral nectar; white symbols), omnivorous (gray symbols), and predatory (black symbols) diets from the following ant genera: 1, Myrmelachista; 2, Nesomyrmex; 3, Cyphomyrmex; 4, Cephalotes; 5, Acromyrmex; 6, Pseudomyrmex; 7, Crematogaster; 8, Brachymyrmex; 9, Dorymyrmex; 10, Paratrechina; 11, Pogonomyrmex; 12, Azteca; 13, Solenopsis (Diplorhoptrum); 14, Pachycondyla; 15, Labidus; 16, Forelius; 17, Neivamyrmex; 18, Ectatomma.

number of intransitivities. For linear hierarchies, this arrangement will cause the majority of wins between species pairs to cluster in the upper right triangle of the matrix (Cerdá et al. 1997, Morrison et al. 2000). To assess matrix linearity, we used the statistical package MatMan version 1.0 (MatMan 1998), which compares the observed matrix with a set of randomized matrices to test whether the observed linearity represents a significant departure from chance (de Vries 1998, LeBrun 2005). In addition to behavioral dominance, we estimated ecological dominance by calculating the fraction of baits captured by each species in the pre-removal sampling period for all stations in which the species was also present in that station's pitfall trap. Ecological dominance thus considers a species' foraging success relative to its abundance (Andersen 1992, LeBrun 2005).

\section{RESULTS}

\section{Stable-isotope analysis}

Stable-isotope analysis indicated that L. humile and $S$. invicta have largely overlapping trophic positions at our two study sites (Fig. 1). At Ocampo, multivariate analysis revealed that the combined isotopic signature of $\delta^{15} \mathrm{~N}$ and $\delta^{13} \mathrm{C}$ differed between $L$. humile and $S$. invicta (Wilks' lambda, 0.551, $F_{2,26}=10.593, P<0.01$ ). Subsequent univariate analyses showed no difference in these species' carbon signatures. However, the mean $\delta^{15} \mathrm{~N}$ value was slightly higher for $S$. invicta (by $1 \%$ ) compared to L. humile (one-way ANOVA, $F_{1,27}=9.736$,
$P<0.02$ ). At Herradura, there was no difference in $\delta^{15} \mathrm{~N}$ or $\delta^{13} \mathrm{C}$ between $S$. invicta and L. humile. As would be expected, stable isotope values for both L. humile and $S$. invicta fell within the range of values obtained from the other omnivorous ants in the system (Fig. 1; C. V. Tillberg and A. V. Suarez, unpublished data).

\section{Activity profiles}

At both Herradura and Ocampo, S. invicta and $L$. humile exhibited similar activity patterns over the course of the diel cycle (Fig. 2). At Ocampo, the less mesic site, foraging activity for both species peaked in the early morning and late evening. At Herradura, S. invicta exhibited a more constant level of activity, while the foraging activity of L. humile peaked in late evening and to a lesser degree in early morning.

\section{Characteristics of the ant communities}

Diverse communities of ground-foraging ants ( $>40$ species) occur at both sites. With respect to species that were attracted to at least $10 \%$ of the bait stations, we observed 11 species at Ocampo and 10 species at Herradura (Table 1). Moreover, four out of the five most common ant species were shared across sites: $L$. humile, S. invicta, Dorymyrmex thorasicus, and Pheidole cf. obscurithorax. This latter species was a common competitor of $S$. invicta and L. humile. Pheidole cf. obscurithorax exhibits morphological characteristics intermediate between $P$. obscurithorax and $P$. jelskii (S. P. Cover, personal communication). Like S. invicta 


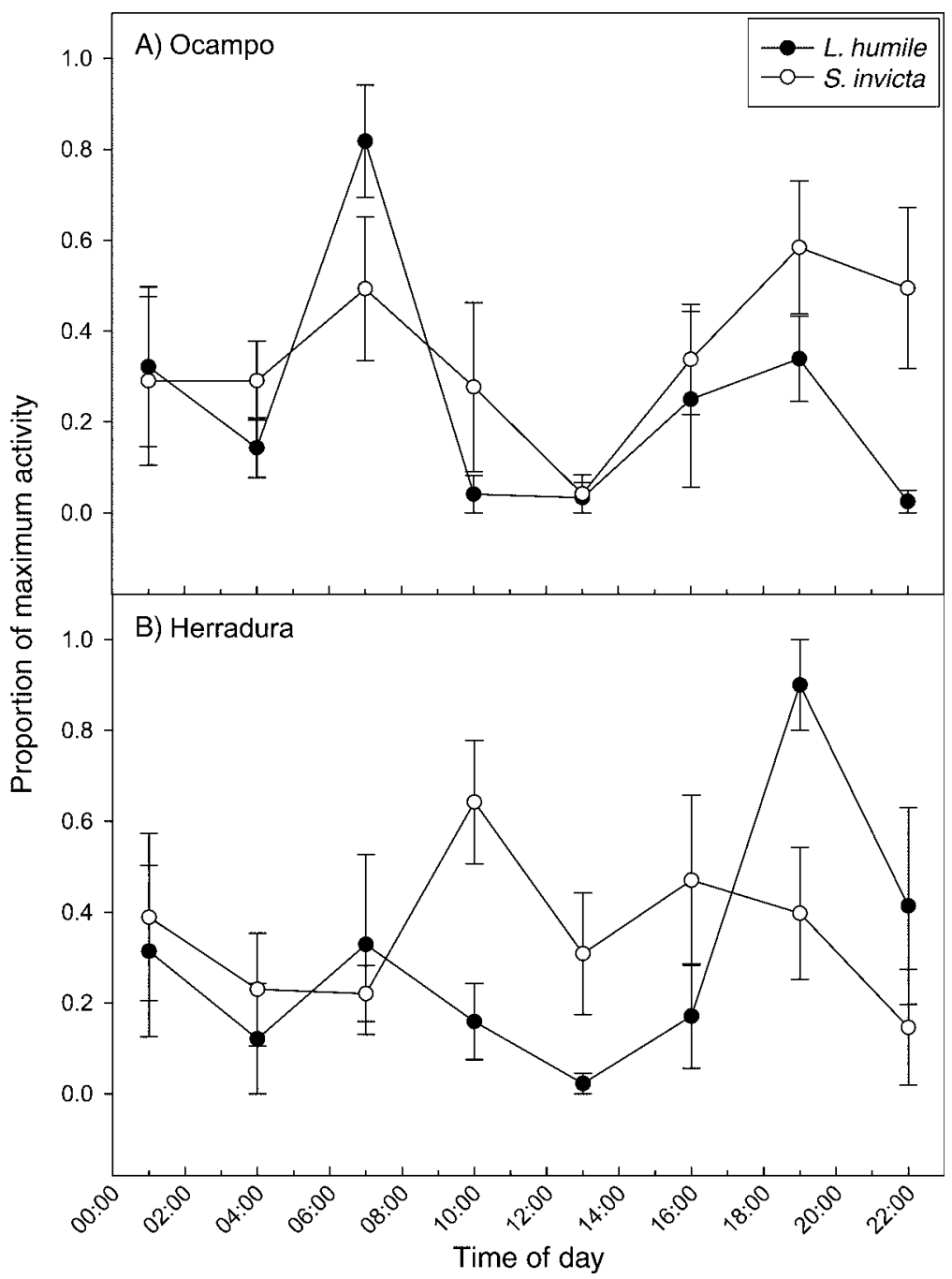

FIG. 2. Activity patterns of Solenopsis invicta and Linepithema humile at (A) Ocampo and (B) Herradura. For each time interval, counts for a plot were transformed into the fraction of the maximum number of workers active in that plot over all sampling periods to yield a proportion of maximum activity measure. The graph shows the means $( \pm \mathrm{SE})$ across all plots of the proportion of maximum activity.

and L. humile, $P$. obscurithorax is native to northern Argentina and Paraguay and has invaded other continents (Storz and Tschinkel 2004). Pheidole cf. obscurithorax differs from $S$. invicta and L. humile in that it employs groups of workers to cooperatively carry large, intact prey items back to its nest.

Analysis of the eight most common competitors at Ocampo revealed a marginally significant, linear hierarchy (Landau's improved linearity index, $h^{\prime}=0.61, P=$ 0.06; Table 2). Solenopsis invicta and L. humile were not the most behaviorally dominant species in this assemblage. Two species, Camponotus blandus and Camponotus punctulatus, proved dominant to both $S$. invicta and L. humile, and Crematogaster quadriformis was dominant to L. humile. Because only one interaction was observed between Crematogaster quadriformis and $S$. invicta, their relative behavioral dominance remains uncertain. Solenopsis invicta succeeded in taking roughly the same number of baits from L. humile (five baits) as L. humile took from $S$. invicta (four baits).

\section{Short-term removal experiment}

The same four species discovered baits most rapidly at our two study sites: L. humile, $S$. invicta, $P$. cf. obscurithorax, and D. thorasicus. At both sites L. humile discovered food resources before $S$. invicta did (Ocampo, likelihood ratio $\chi^{2}=7.1, \mathrm{df}=2, N=33, P<0.03$; Herradura, likelihood ratio $\chi^{2}=11.1, \mathrm{df}=2, N=24, P$ $<$ 0.004). Resource discovery was uniformly rapid. Average discovery time by any ant was $1.8 \pm 3.1 \mathrm{~min}$ at Ocampo (mean \pm SD) and $1.1 \pm 1.7 \mathrm{~min}$ at Herradura. These rapid dynamics mean that interspecific differences in mean discovery times were small; $L$. humile discovered resources, on average, $4.1 \mathrm{~min}$ faster compared to $S$. 
Table 1. Ant species at the Herradura and Ocampo field sites in northern Argentina that were observed at a minimum of $10 \%$ of bait stations employed in the short-term removal experiment.

\begin{tabular}{lc}
\hline \hline \multicolumn{1}{c}{ Species } & $\begin{array}{c}\text { Prevalence } \\
\text { at baits }\end{array}$ \\
\hline Ocampo & \\
Camponotus blandus & 0.22 \\
Camponotus punctulatus & 0.15 \\
Crematogaster quadriformis & 0.11 \\
Dorymyrmex thorasicus & 0.55 \\
Linepithema humile & 0.96 \\
Paratrechina cf. fulva & 0.19 \\
Pheidole sp. A & 0.11 \\
Pheidole cf. obscurithorax & 0.52 \\
Solenopsis invicta & 0.74 \\
Solenopsis substituta & 0.26 \\
Wasmannia auropunctata & 0.11 \\
Herradura & \\
Crematogaster quadriformis & \\
Dorymyrmex thorasicus & 0.41 \\
Ectatomma edentatum & 0.26 \\
Linepithema humile & 0.19 \\
Pheidole sp. A & 0.81 \\
Pheidole cf. obscurithorax & 0.11 \\
Pheidole sp. B & 1.00 \\
Pseudomyrmex denticollis & 0.22 \\
Solenopsis invicta & 0.26 \\
Solenopsis (Diplorhoptrum) sp. A & 0.78 \\
\hline
\end{tabular}

Note: Prevalence equals the fraction of bait stations at which each species was observed foraging.

invicta at Ocampo and 2.5 min more quickly at Herradura. There were insufficient observations to test $P$. cf. obscurithorax and D. thorasicus independently. However, discovery order did not differ between $L$. humile and $P$. cf. obscurithorax $+D$. thorasicus (Ocampo, likelihood ratio $\chi^{2}=2.8, \mathrm{df}=2, N=34, P=0.24$; Herradura, likelihood ratio $\chi^{2}=0.29, \mathrm{df}=2, N=36, P=$ $0.87)$.
Relative densities of $S$. invicta and L. humile workers strongly influenced the outcome of competition in control trials. Logistic regression revealed that the difference between the number of $L$. humile and $S$. invicta captured in pitfall traps significantly predicts the outcome of competition (Ocampo, $N=11$, odds ratio = 1.6, $G^{2}=4.6, P<0.03$; Herradura, $N=9$, odds ratio $=$ $\left.1.8, G^{2}=7.5, P<0.006\right)$. This relationship is also evident when the relative numbers of workers captured in pitfall traps at plot corners in the colony removal experiment are compared to the outcome of the preremoval baiting sample at those same locations (logistic regression, $N=64$, odds ratio $=1.2, G^{2}=28.5, P<$ 0.0001 ; Fig. 3). There was no significant difference between sites in the abundance of either L. humile or $S$. invicta in pitfall traps (Kruskal-Wallis test, L. humile, $N$ $=20, Z=1.5, P=0.13 ;$ S. invicta, $N=20, Z=0.0, P=$ $1.0)$.

At both Herradura and Ocampo, exclusion of $L$. humile from baits enhanced the ability of $S$. invicta to capture baits (Ocampo, goodness-of-fit $\chi^{2}=4.66, \mathrm{df}=1$, $N=23$, one-tailed $P<0.03$; Herradura, goodness-of-fit $\chi^{2}=4.42$, df $=1, N=16$, one-tailed $P<0.03$ ), while exclusion of $S$. invicta did not increase the likelihood of bait capture by L. humile (Ocampo, goodness-of-fit $\chi^{2}=$ 0.708 , df $=1$, one-tailed $P=0.25$; Herradura, goodnessof-fit $\chi^{2}=2.618, \mathrm{df}=1$, one-tailed $P=0.88$; Fig. 4). Loglinear analysis, however, revealed no difference in the strength of competitive release exhibited by $S$. invicta and L. humile (Ocampo, likelihood ratio $\chi^{2}=0.03, \mathrm{df}=$ $1, P=0.87$; Herradura, likelihood ratio $\chi^{2}=3.17, \mathrm{df}=1$, $P=0.08$; Fig. 4). There was also no difference between sites in the degree to which either S. invicta or L. humile was competitively released by the removal of the other (log-linear analysis, $S$. invicta, likelihood ratio $\chi^{2}=0.02$, $\mathrm{df}=1, P=0.88 ;$ L. humile, likelihood ratio $\chi^{2}=1.49$, df $=1, P=0.22$ ).

TABLE 2. Behavioral dominance matrix for the ant community at Ocampo.

\begin{tabular}{|c|c|c|c|c|c|c|c|c|c|c|c|c|}
\hline Species & C. bla. & C. pun. & $\underline{\text { S. inv. }}$ & Cr. qu. & L. hum. & P. obs. & D. tho. & S. sub. & Total & $\begin{array}{l}\text { Behavioral } \\
\text { dominance }\end{array}$ & $\begin{array}{c}\text { Relative } \\
\text { abundance }\end{array}$ & $\begin{array}{l}\text { Ecological } \\
\text { dominance }\end{array}$ \\
\hline C. bla. & $\cdots$ & & 1 & & & 2 & 3 & 1 & 7 & 1 & 0.02 & na \\
\hline C. pun. & & $\cdots$ & 4 & & 3 & 2 & 2 & & 11 & 1 & 0.17 & 0.25 \\
\hline S. inv. & 0 & 0 & $\cdots$ & 1 & $\underline{5}$ & 8 & 13 & 2 & 29 & 0.74 & 0.98 & 0.26 \\
\hline$\overline{C r . q u}$ & & & 0 & $\ldots$ & $\overline{4}$ & 2 & 1 & & 7 & 0.88 & 0.05 & 0.20 \\
\hline L. hum. & & 0 & $\underline{4}$ & 0 & $\cdots$ & 7 & 10 & 2 & 23 & 0.66 & 0.98 & 0.55 \\
\hline$\overline{P . \text { obs. }}$ & 0 & 0 & $\overline{1}$ & 0 & 0 & $\ldots$ & 2 & & 3 & 0.13 & 0.45 & 0 \\
\hline D. tho. & 0 & 0 & 0 & 0 & 0 & 0 & $\cdots$ & 3 & 3 & 0.09 & 0.48 & 0.05 \\
\hline S. sub. & 0 & & 0 & & 0 & & 1 & $\cdots$ & 1 & 0.11 & 0.35 & 0 \\
\hline Total & 0 & 0 & 10 & 1 & 12 & 21 & 32 & 8 & 84 & $P=0.06$ & & \\
\hline
\end{tabular}

Notes: Cell entries show the outcome of competitive interactions at baits. Rows list the number of interactions won; columns list interactions lost. Boldface type indicates the cell containing the majority of wins for that interaction. Empty cells are species combinations for which no interactions were observed. The focal species, Linepithema humile and Solenopsis invicta, and their interactions with one another are underlined. Behavioral dominance is the proportion of interactions won; the $P$ value reported at the bottom of that column provides a measure of whether the observed matrix is more linear than would be expected by chance. Relative abundance is the proportion of pitfall traps that captured each species. Ecological dominance was estimated as the fraction of baits that a species controlled for all stations at which it was captured in pitfall traps. Species not sufficiently common in pitfall traps to calculate an ecological dominance score are indicated with "na." Abbreviations are: S. inv., S. invicta; C. bla., Camponotus blandus; C. pun., Camponotus punctulatus; Cr. qu., Crematogaster quadriformis; L. hum., L. humile; P. obs., Pheidole obscurithorax; D. tho., Dorymyrmex thorasicus; S. sub., Solenopsis substituta. 


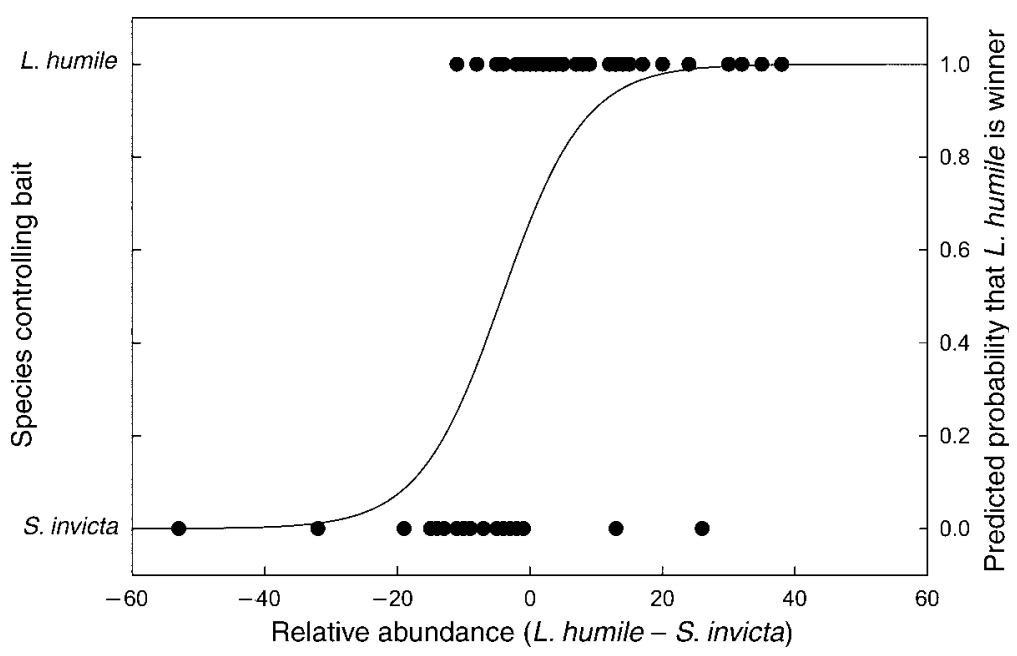

FIG. 3. Outcome of competition between Linepithema humile and Solenopsis invicta for pre-manipulation baiting from the colony removal experiment: logistic regression of the species that captured the corner baits vs. its relative abundance.

\section{Colony removal experiment}

Prior to colony removals, treatment plots did not differ with respect to the mean number of S. invicta and L. humile captured in pitfall traps (two-sample $t$ test, $t=$ $1.1, \mathrm{df}=12, P=0.25$ ) or in the proportion of traps that captured these two species (out of 108 traps, 70 captured S. invicta and 72 captured L. humile). Within plots, however, S. invicta and $L$. humile tended to control mutually exclusive areas. By considering traps that contained a median number of S. invicta or L. humile workers, we found that these species co-occurred at or above median densities substantially less often than would be expected by chance (EcoSim null model analysis, observed $C$ score $=483$, expected $C$ score $=$ $160, P<0.0001)$. This segregation is evident in the nonoverlapping pattern of bait capture in the premanipulation sample (see Appendix B).

While colony removal treatments greatly reduced the abundance of $S$. invicta and $L$. humile, neither species was entirely eliminated. In post-removal sampling, for example, $S$. invicta succeeded in capturing $26 \% \pm 9 \%$ (means $\pm \mathrm{SE}$ ) of the bait stations that it captured in the pre-removal sampling, while L. humile captured $38 \% \pm$ $10 \%$ of the bait stations it captured in the pre-removal sampling. Measured in this way, the effectiveness of the treatments did not differ between the two species (twosample $t$ test, $t=0.79, \mathrm{df}=11, P=0.44$ ).

Reciprocal colony removal of $S$. invicta and L. humile released the unremoved focal species from competition (Fig. 5). The degree of this release was fairly symmetric. Linepithema humile captured $32 \%$ more bait stations previously held by $S$. invicta in removal plots compared to control plots (two-sample $t$ test, $t=-3.3$, $\mathrm{df}=9$, onetailed $P<0.005$ ), whereas $S$. invicta captured $20 \%$ more bait stations previously held by $L$. humile in removal plots compared to control plots (two-sample $t$ test, $t=-2.3$, df
$=11$, one-tailed $P<0.02$; Fig. 5). Combining all baits taken by species aside from the focal competitors, other ant species exhibited a significant release from competition in the $L$. humile removal plots (two-sample $t$ test, $t=$ $-4.0, \mathrm{df}=6$, one-tailed $P<0.004$ ) but not in the $S$. invicta
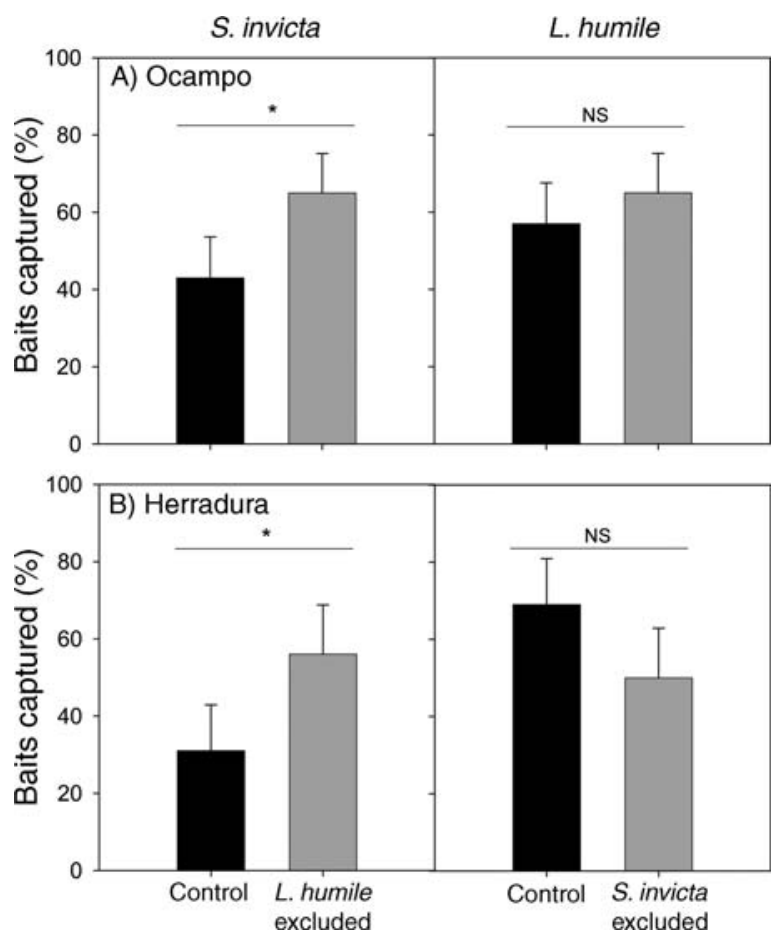

FIG. 4. Tests of competitive release from the short-term removal experiment conducted at (A) Ocampo and (B) Herradura showing the percentage of all baits captured (mean $+\mathrm{SE})$ by Solenopsis invicta and Linepithema humile in the presence and absence of one another. Asterisks indicate significant differences $(P<0.05)$. 
removal plots (two-sample $t$ test, $t=-1.0, \mathrm{df}=11$, onetailed $P=0.17$ ). However, the absolute magnitude of the response of other ant species to the removal of the focal competitors was roughly similar (Fig. 5).

\section{Discussion}

Activity surveys and stable-isotope analyses demonstrate the potential for interspecific competition between S. invicta and L. humile. At multiple locations in Ocampo and Herradura, fire ants and Argentine ants exhibited broadly overlapping foraging activity periods (Fig. 2). Temporal overlap was greatest at Ocampo. In addition to foraging at the same times, stable isotope signatures indicate that these species occupy similar trophic positions (Fig. 1). At both study sites, S. invicta and L. humile belong to diverse assemblages of omnivorous ants and have diets intermediate between highly predaceous species, such as army ants, and species that mostly consume plant exudates, honeydew, or seeds (Tillberg et al. 2006) (Fig. 1). Nitrogen isotope signatures for $L$. humile and $S$. invicta did not significantly differ at Herradura but did diverge slightly at Ocampo, with $S$. invicta having a $1 \%$ more enriched signal. The magnitude of this difference, however, is insufficient to place L. humile and S. invicta on different trophic levels. Cabana and Rasmussen (1994), for example, found that consumers from different trophic levels tend to be enriched by $\sim 3 \%$ per trophic level. The difference in nitrogen isotope signatures between $L$. humile and $S$. invicta from Ocampo may reflect interspecific differences in predatory behavior or honeydew consumption. These data on temporal and trophic overlap combined with the observation of frequent, intense conflicts over both artificial and natural food items indicate that these two species compete strongly.

Although literature accounts suggest that S. invicta may be a superior competitor to L. humile, at least in the southeastern United States, we found little evidence for such a competitive asymmetry at our study sites in Argentina. In unmanipulated trials $S$. invicta and $L$. humile exhibited comparable abilities to take over baits from one another (Table 2). Control of this type of resource depended upon disparities in the local density of each species (Fig. 3). Interestingly, the inflection point for the logistic curve illustrated in Fig. 3 falls close to zero, which is the expectation for symmetric competition. The outcome of our short-term removal experiments again revealed evidence inconsistent with the notion that $S$. invicta is superior to $L$. humile in competitive ability. Our results, in fact, suggest the opposite. Solenopsis invicta captured more baits in the absence of $L$. humile than when L. humile was present, but we observed no such competitive release for $L$. humile when we removed S. invicta. Lastly, and perhaps most convincingly, our colony removal experiments provide little evidence for a competitive asymmetry between $S$. invicta and L. humile. Local worker densities
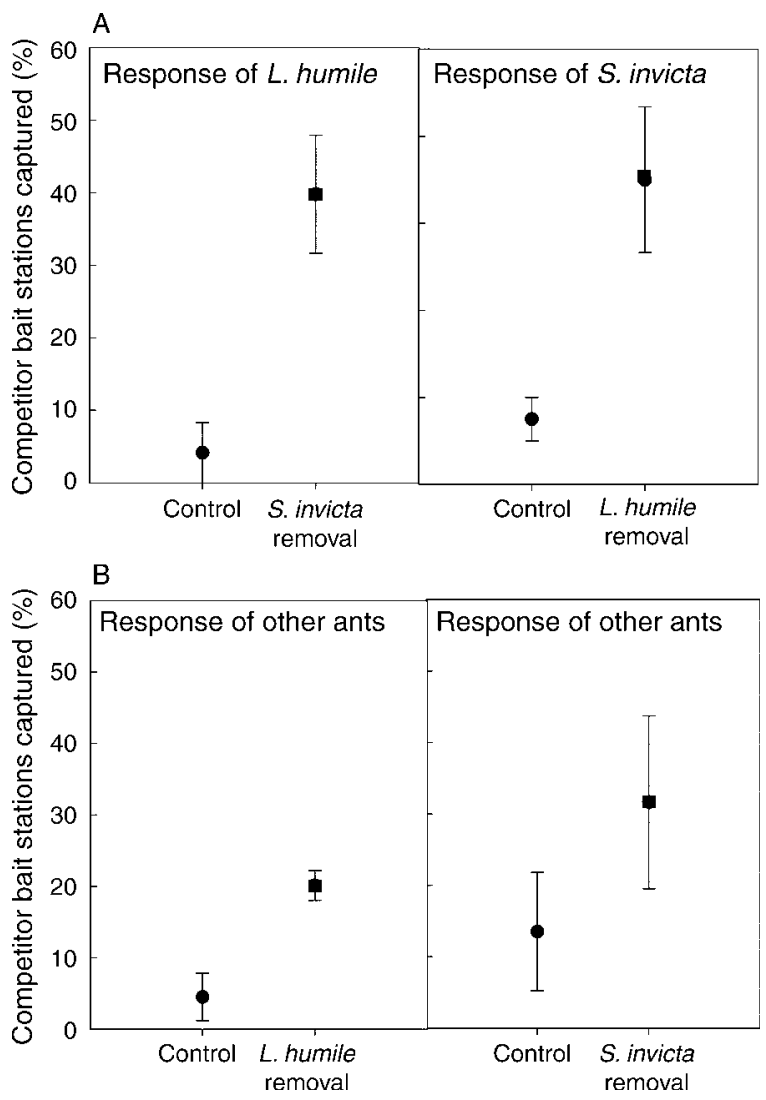

FIG. 5. Results of the colony removal experiment (mean \pm SE). (A) Response of Linepithema humile and Solenopsis invicta to the removal of one another's colonies. Competitive release was measured as the percentage of the bait stations captured by the competitor species in the pre-manipulation sample that the focal species captured in the final sample. (B) Response of species of ants other than $L$. humile and $S$. invicta to the removal of these two focal competitors.

of these two species are negatively associated, which in combination with the strong influence of worker densities on the outcome of competition (Fig. 3), results in areas in which resources are exclusively controlled by one or the other species (see Appendix B). When we removed colonies at the scale of $10 \times 10 \mathrm{~m}$ plots, both species displayed a substantial, and approximately equal, release from interspecific competition.

What do these results tell us about ecological coexistence between these two dominant and outwardly similar competitors? Both S. invicta and L. humile are omnivorous scavenging species that rely on rapid, mass recruitment to capture food items. Moreover, our reciprocal removal experiments point to strong and roughly symmetric competition between $S$. invicta and L. humile. The inverse relationship between the local densities of these competitors in places where they cooccur (Fig. 3) and the frequency of habitat patches that contain only one or the other species, but not both, suggests an unstable, condition-dependent coexistence. 
The competitive symmetry and apparently unstable coexistence observed in floodplain habitats in Argentina suggests that local displacement of one species by the other is likely when these species come into contact outside of their native range. However, the displacement of L. humile by $S$. invicta from all but limited refugia, as occurred in the southeastern United States, may not be the rule. Differences in habitat, social form (Porter et al. 1991, Mescher et al. 2003), degree of unicoloniality (Tsutsui et al. 2000, Buczkowski et al. 2004, Holway and Suarez 2004), and prevalence of natural enemies (Porter et al. 1992) between the introduced and native ranges of these species, as well as between distinct parts of their introduced ranges, make specific predictions about the conditions favoring one species over another difficult. However, our finding of highly symmetric competitive abilities in Argentina indicates the potential for dynamic change in these species' competitive balance. Special attention should be paid to these species' interactions in new areas of secondary contact, such as California and Australia, as well as in old areas of secondary contact, such as the southeastern United States, where S. invicta is reacquiring its load of natural enemies (Williams et al. 1998, Morrison and Porter 2005, Porter and Gilbert 2005).

Based on our understanding of this system, flooding events might be a key factor in promoting coexistence between $S$. invicta and $L$. humile. The river floodplain woodlands and savannas are subject annually to floods of variable duration and magnitude. There were no obvious habitat differences between areas containing high densities of $L$. humile and those with high densities of $S$. invicta. However, these species exhibit unique strategies to cope with inundation. Argentine ants retreat temporally into trees and other emergent vegetation, housing brood and queens inside dead limbs, under loose bark, or in dense clumps of leaves. Solenopsis invicta, in contrast, occupies the apical portions of its nest mounds and will float en masse to higher ground if mounds become completely submerged. At our study sites, it seems likely that flooding events restrict $S$. invicta and $L$. humile to species-specific microhabitats that provide suitable refuges from flooding. The ability of these species to respond rapidly to disturbances, such as flooding events, may predispose them for success in the human-modified environments of their introduced ranges.

An additional goal of this study was to examine whether or not $S$. invicta and L. humile achieve the extreme levels of behavioral or ecological dominance documented for introduced populations of both species. Both S. invicta and (especially) L. humile discovered food resources quickly. However, in contrast to studies from the introduced range (Porter and Savignano 1990, Holway 1999), neither species stood out as being an exceptionally fast discoverer of food resources relative to other species in the assemblage. Moreover, the bait turnover data in Table 2 indicate that neither $S$. invicta nor $L$. humile is the most behaviorally dominant species in these communities. This situation differs from the results of studies from the United States that typically show $S$. invicta and $L$. humile to be the most behaviorally dominant taxon in areas where either of these two species is common (Porter and Savignano 1990, Holway 1999). For reasons that remain unclear, ants that were behaviorally dominant to $S$. invicta and $L$. humile were relatively rare in the habitats sampled.

Solenopsis invicta and especially L. humile were among the most ecologically dominant species in the assemblage as measured by their ability to monopolize large, persistent food resources (Table 2). The apparently higher ecological dominance of $L$. humile relative to $S$. invicta may arise because $S$. invicta colonies were less often actively foraging (E. G. LeBrun, C. V. Tillberg, and D. A. Holway, personal observations). Reflecting the difference in ecological dominance, other omnivorous ant species captured more baits with the removal of L. humile colonies, but the response of these other ant species to the removal of $S$. invicta colonies, although of similar magnitude, was too variable to be significant (Fig. 5). Multiple species achieve ecological dominance in the presence of both red imported fire ants and Argentine ants (Table 2). The ecological dominance of these species in areas with both S. invicta and L. humile again contrasts sharply with invaded communities in North America (Porter and Savignano 1990, Holway 1999). The use of large resources, although justified in this system, may underestimate the competitive ability of larger bodied species and species such as $P$. cf. obscurithorax, which excel at the retrieval of smaller food items. Limited observations of insect baits, for example, indicated that $P$. cf. obscurithorax is highly proficient at capturing these smaller resources.

An unresolved question in invasion biology is the degree to which populations of introduced species, especially animals, are limited in their native ranges by interspecific competitors. We found that in the native ranges of two important invasive species, L. humile and S. invicta restrict each other's ability to forage and to capture food resources. These effects likely translate into reduced colony growth, reduced reproductive output, and ultimately smaller population sizes. Moreover, a number of ant species in these systems exhibit competitive abilities that appear equal to or greater than those of $L$. humile and $S$. invicta. While not diminishing the potential importance of escape from coevolved enemies (Porter et al. 1997) or behavioral changes that occurred following introduction into new environments (Ross et al. 1996, Tsutsui et al. 2000), these findings strongly suggest that release from interspecific competition contributes importantly to the success of $L$. humile and $S$. invicta when these species are introduced into new environments. This effect may be heightened by strong biogeographical 
disparities in the importance of interspecific competition between ant communities in North and South America. The floodplains of central South America have the remarkable distinction of being the native range for a number of invasive ants including $S$. invicta, $S$. richteri, L. humile, $P$. obscurithorax, Wasmannia auropunctata, Pseudomyrmex gracilis, and Paratrechina fulva. The dual pressures of intense interspecific competition and frequent flooding may have selected for species-level traits that make these ants inherently proficient invaders. Moreover, the proximity of this region to major port cites (e.g., Buenos Aires, Rosario, Asunción) make it particularly important as a source of both current and potential invasive species.

\section{ACKNOWLEDGMENTS}

This research was supported by NSF-INT (0305773) to D. A. Holway and A. V. Suarez and NSF-DEB (0516452) to A.V. Suarez and C. V. Tillberg. We thank A. Pividori and O. Pividori for generously allowing us permission to work on their property. For help with fieldwork, we thank L. Calcaterra, J. Holley, S. Menke, and I. C. Quilmes. W. Tschinkel and N. Gotelli provided crucial technical advice. A. Wild, S. Cover, P. Ward, and J. Longino provided invaluable advice on the identification of ant specimens. P. Folgarait acknowledges CONICET and Universidad Nacional de Quilmes.

\section{Literature Cited}

Allen, G. E., W. F. Buren, R. N. Williams, M. Demeneze, and W. H. Whitcomb. 1974. Red imported fire ant, Solenopsis invicta - distribution and habitat in Mato Grosso, Brazil. Annals of the Entomological Society of America 67:43-46.

Andersen, A. N. 1992. Regulation of "momentary" diversity by dominant species in exceptionally rich ant communities of the Australian seasonal tropics. American Naturalist 140:401420.

Buczkowski, G., E. L. Vargo, and J. Silverman. 2004. The diminutive supercolony: the Argentine ants of the southeastern United States. Molecular Ecology 13:2235-2242.

Buren, W. F., G. E. Allen, W. H. Whitcomb, F. E. Lennartz, and R. N. Williams. 1974. Zoogeography of imported fire ants. Journal of the New York Entomological Society 82: 113-124.

Cabana, G., and J. B. Rasmussen. 1994. Modeling food-chain structure and contaminant bioaccumulation using stable nitrogen isotopes. Nature 372:255-257.

Callaway, R. M., and E. T. Aschehoug. 2000. Invasive plants versus their new and old neighbors: a mechanism for exotic invasion. Science 290:521-523.

Cerdá, X., J. Retana, and S. Cros. 1997. Thermal disruption of transitive hierarchies in Mediterranean ant communities. Journal of Animal Ecology 66:363-374.

De Bach, P. 1974. Biological control by natural enemies. Cambridge University Press, London, UK.

Deniro, M. J., and S. Epstein. 1981. Influence of diet on the distribution of nitrogen isotopes in animals. Geochimica et Cosmochimica Acta 45:341-351.

de Vries, H. 1998. Finding a dominance order most consistent with a linear hierarchy: a new procedure and review. Animal Behavior 55:827-843.

Elton, C. S. 1958. The ecology of invasions by animals and plants. Methuen, London, UK.

Feener, D. H., Jr. 2000. Is the assembly of ant communities mediated by parasitoids? Oikos 90:79-88.

Glancey, B. M., D. P. Wojcik, C. H. Craig, and J. A. Mitchell. 1976. Ants of Mobile County, AL as monitored by bait transects. Journal of the Georgia Entomological Society 11: 191-197.

Gotelli, N. J. 2000. Null model analysis of species co-occurrence patterns. Ecology 81:2606-2621.

Gotelli, N. J., and G. L. Entsminger. 2004. EcoSim: null models software for ecology. Acquired Intelligence and Kesey-Bear, Jericho, Vermont, USA.

Holway, D. A. 1999. Competitive mechanisms underlying the displacement of native ants by the invasive argentine ant. Ecology 80:238-251.

Holway, D. A., and A. V. Suarez. 2004. Colony-structure variation and interspecific competitive ability in the invasive Argentine ant. Oecologia 138:216-222.

Human, K. G., and D. M. Gordon. 1996. Exploitation and interference competition between the invasive Argentine ant, Linepithema humile, and native ant species. Oecologia 105: 405-412.

Lajtha, K., and R. H. Michener, editors. 1994. Stable isotopes in ecology and environmental science. Oxford Press, Boston, Massachusetts, USA.

LeBrun, E. G. 2005. Who's the top dog in ant communities? Resources, parasitoids, and multiple competitive hierarchies. Oecologia 142:643-652.

MatMan. 1998. MatMan. Version 1.0 for Windows. Noldus Information Technology, Wageningen, The Netherlands.

McCutchan, J. H., W. M. Lewis, C. Kendall, and C. C. McGrath. 2003. Variation in trophic shift for stable isotope ratios of carbon, nitrogen, and sulfur. Oikos 102:378390.

Mescher, M. C., K. G. Ross, D. D. Shoemaker, L. Keller, and M. J. B. Krieger. 2003. Distribution of the two social forms of the fire ant Solenopsis invicta (Hymenoptera: Formicidae) in the native South American range. Annals of the Entomological Society of America 96:810-817.

Mitchell, C. E., and A. G. Power. 2003. Release of invasive plants from fungal and viral pathogens. Nature 421:625-627.

Morrison, L. W. 2000. Mechanisms of interspecific competition among an invasive and two native fire ants. Oikos 90:238252.

Morrison, L. W., E. A. Kawazoe, R. Guerra, and L. E. Gilbert. 2000. Ecological interactions of Pseudacteon parasitoids and Solenopsis ant hosts: environmental correlates of activity and effects on competitive hierarchies. Ecological Entomology 25: 433-444.

Morrison, L. W., and S. D. Porter. 2005. Testing for population-level impacts of introduced Pseudacteon tricuspis flies, phorid parasitoids of Solenopsis invicta fire ants. Biological Control 33:9-19.

Morrison, L. W., S. D. Porter, E. Daniels, and M. D. Korzukhin. 2004. Potential global range expansion of the invasive fire ant, Solenopsis invicta. Biological Invasions 6: 183-191.

Pitts, J. P. 2002. A cladistic analysis of the Solenopsis saevissima species-group (Hymenoptera: Formicidae). Dissertation. University of Georgia, Athens, Georgia, USA.

Porter, S. D., A. Bhatkar, R. Mulder, S. B. Vinson, and D. J. Clair. 1991. Distribution and density of polygyne fire ants (Hymenoptera, Formicidae) in Texas. Journal of Economic Entomology 84:866-874.

Porter, S. D., H. G. Fowler, and W. P. Mackay. 1992. Fire ant mound densities in the United-States and Brazil (Hymenoptera, Formicidae). Journal of Economic Entomology 85: $1155-1161$.

Porter, S. D., and L. E. Gilbert. 2005. Assessing host specificity and field release potential of fire ant decapitating flies (Phoridae: Pseudacteon). Pages 152-176 in R. G. Van Driesche and R. Reardon, editors. Assessing host ranges for parasitoids and predators used for classical biological control: a guide to best practice. Forestry Health Technology Enterprise Team (FHTET) publication 2004-03. USDA Forest Service, Morgantown, West Virginia, USA. 
Porter, S. D., and D. A. Savignano. 1990. Invasion of polygyne fire ants decimates native ants and disrupts arthropod community. Ecology 71:2095-2106.

Porter, S. D., D. F. Williams, R. S. Patterson, and H. G. Fowler. 1997. Intercontinental differences in the abundance of Solenopsis fire ants (Hymenoptera: Formicidae): Escape from natural enemies? Environmental Entomology 26:373384.

Post, D. M. 2002. Using stable isotopes to estimate trophic position: models, methods, and assumptions. Ecology 83: 703-718.

Quinn, G. P., and M. J. Keough. 2002. Experimental design and data analysis for biologists. Cambridge University Press, Cambridge, UK.

Ross, K. G., and J. C. Trager. 1990. Systematics and population genetics of fire ants (Solenopsis saevissima complex) from Argentina. Evolution 44:2113-2134.

Ross, K. G., E. L. Vargo, and L. Keller. 1996. Social evolution in a new environment: the case of introduced fire ants. Proceedings of the National Academy of Sciences (USA) 93: 3021-3025.

Roura-Pascual, N., A. V. Suarez, C. Gomez, P. Pons, Y. Touyama, A. L. Wild, and A. T. Peterson. 2004. Geographical potential of Argentine ants (Linepithema humile Mayr) in the face of global climate change. Proceedings of the Royal Society of London B 271:2527-2534.

Sokal, R. R., and F. J. Rohlf. 2000. Biometry. W.H. Freeman, New York, New York, USA.

Stone, L., and A. Roberts. 1990. The checkerboard score and species distributions. Oecologia 85:74-79.

Storz, S. R., and W. R. Tschinkel. 2004. Distribution, spread, and ecological associations of the introduced ant Pheidole obscurithorax in the southeastern United States. Journal of Insect Science 4:1-11.

Suarez, A. V., D. A. Holway, and T. J. Case. 2001. Patterns of spread in biological invasions dominated by long-distance jump dispersal: insights from Argentine ants. Proceedings of the National Academy of Sciences (USA) 98:10951100 .

Suarez, A. V., N. D. Tsutsui, D. A. Holway, and T. J. Case. 1999. Behavioral and genetic differentiation between native and introduced populations of the Argentine ant. Biological Invasions 1:1-11.

Tillberg, C. V., D. P. McCarthy, A. G. Dolezal, and A. V. Suarez. 2006. Measuring the trophic ecology of ants using stable isotopes. Insectes Sociaux 53:65-69.

Tilman, D. 1999. The ecological consequences of changes in biodiversity: a search for general principles. Ecology 80: 1455-1474.

Torchin, M. E., K. D. Lafferty, A. P. Dobson, V. J. McKenzie, and A. M. Kuris. 2003. Introduced species and their missing parasites. Nature 421:628-630.

Tschinkel, W. R., E. S. Adams, and T. Macom. 1995. Territory area and colony size in the fire ant Solenopsis invicta. Journal of Animal Ecology 64:473-480.

Tsutsui, N. D., A. V. Suarez, D. A. Holway, and T. J. Case. 2000. Reduced genetic variation and the success of an invasive species. Proceedings of the National Academy of Sciences (USA) 97:5948-5953.

Tsutsui, N. D., A. V. Suarez, D. A. Holway, and T. J. Case. 2001. Relationships among native and introduced populations of the Argentine ant (Linepithema humile) and the source of introduced populations. Molecular Ecology 10: 2151-2161.

Vanderklift, M. A., and S. Ponsard. 2003. Sources of variation in consumer-diet delta N-15 enrichment: a meta-analysis. Oecologia 136:169-182.

Vermeij, G. J. 1991. When biotas meet: understanding biotic interchange. Science 253:1099-1104.

Wild, A. L. 2004. Taxonomy and distribution of the Argentine ant, Linepithema humile (Hymenoptera : Formicidae). Annals of the Entomological Society of America 97:1204-1215.

Williams, D. F., G. J. Knue, and J. J. Becnel. 1998. Discovery of Thelohania solenopsae from the red imported fire ant, Solenopsis invicta, in the United States. Journal of Invertebrate Pathology 71:175-176.

Wilson, E. O. 1951. Variation and adaptation in the imported fire ant. Evolution 5:68-79.

Wolfe, L. M. 2002. Why alien invaders succeed: support for the escape-from-enemy hypothesis. American Naturalist 160: 705-711.

\section{APPENDIX A}

A map of northern Argentina showing the location of the study sites and the region of native-range overlap for $S$. invicta and $L$. humile (Ecological Archives E088-004-A1).

\section{APPENDIX B}

A diagram illustrating the nonoverlapping pattern of bait capture in the colony removal plots before manipulation (Ecological Archives E088-004-A2). 
Edward G. LeBrun, Chadwick V. Tillberg, Andrew V. Suarez, Patricia J. Folgarait, Chris

R. Smith, and David A. Holway. 2006. An experimental study of competitive interactions between red imported fire ants and Argentine ants in a region of native-range sympatry. Ecology

Appendix A. A map of northern Argentina.
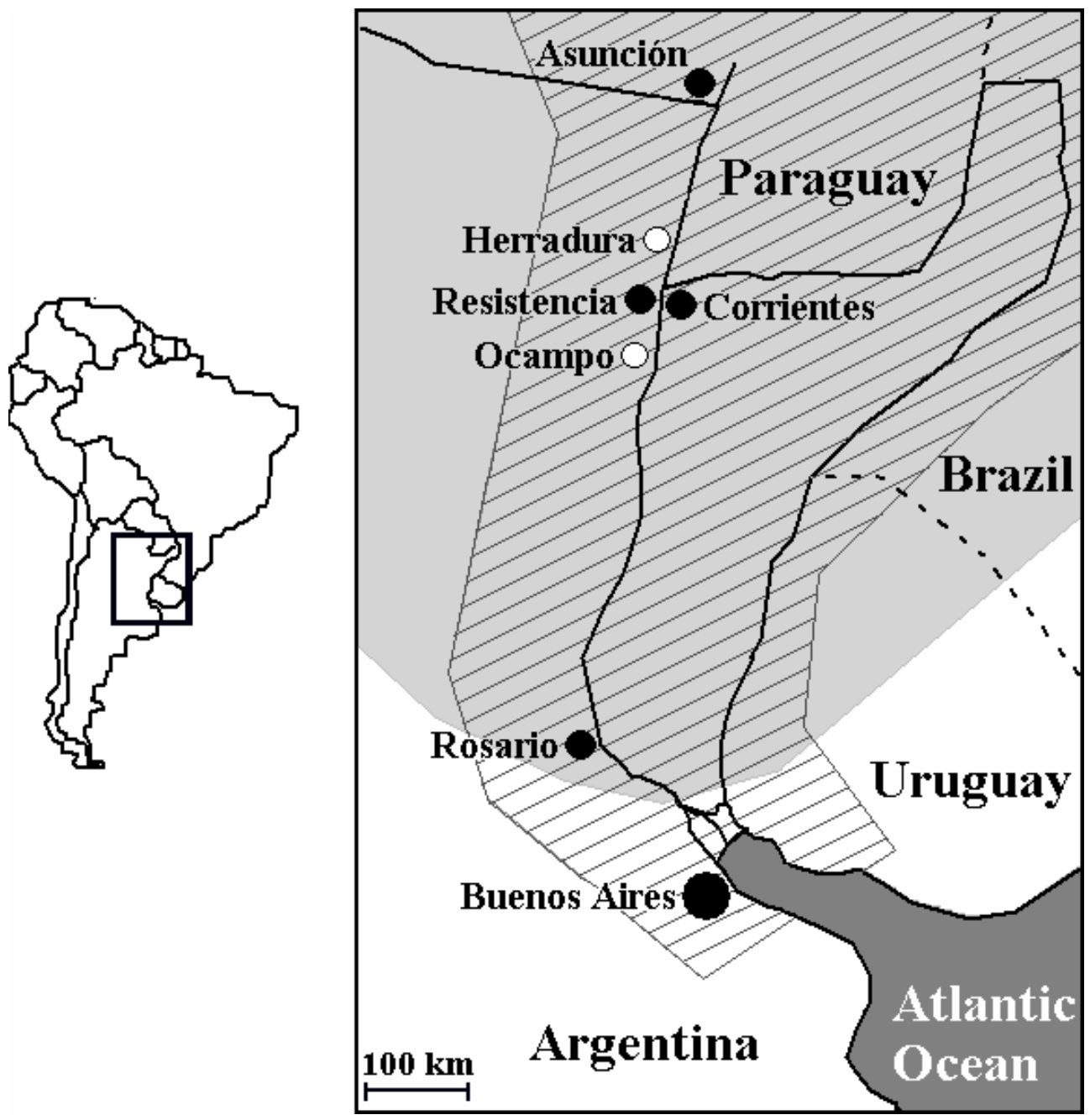

Fig. A1. Map of northern Argentina illustrating the overlap in the distributions of S. invicta (light grey shading) and L. humile (diagonal hatching). Solid lines represent major rivers and the dark grey shading represents the Rio de la Plata and Atlantic Ocean. Dashed lines represent country borders. Major port cities (closed circles) and the two study sites (open circles) are also featured. 
Edward G. LeBrun, Chadwick V. Tillberg, Andrew V. Suarez, Patricia J. Folgarait, Chris R. Smith, and David A. Holway. 2006. An experimental study of competitive interactions between red imported fire ants and Argentine ants in a region of native-range sympatry. Ecology

Appendix B. Diagram illustrating the non-overlapping pattern of bait capture in the colony removal plots pre-manipulation.

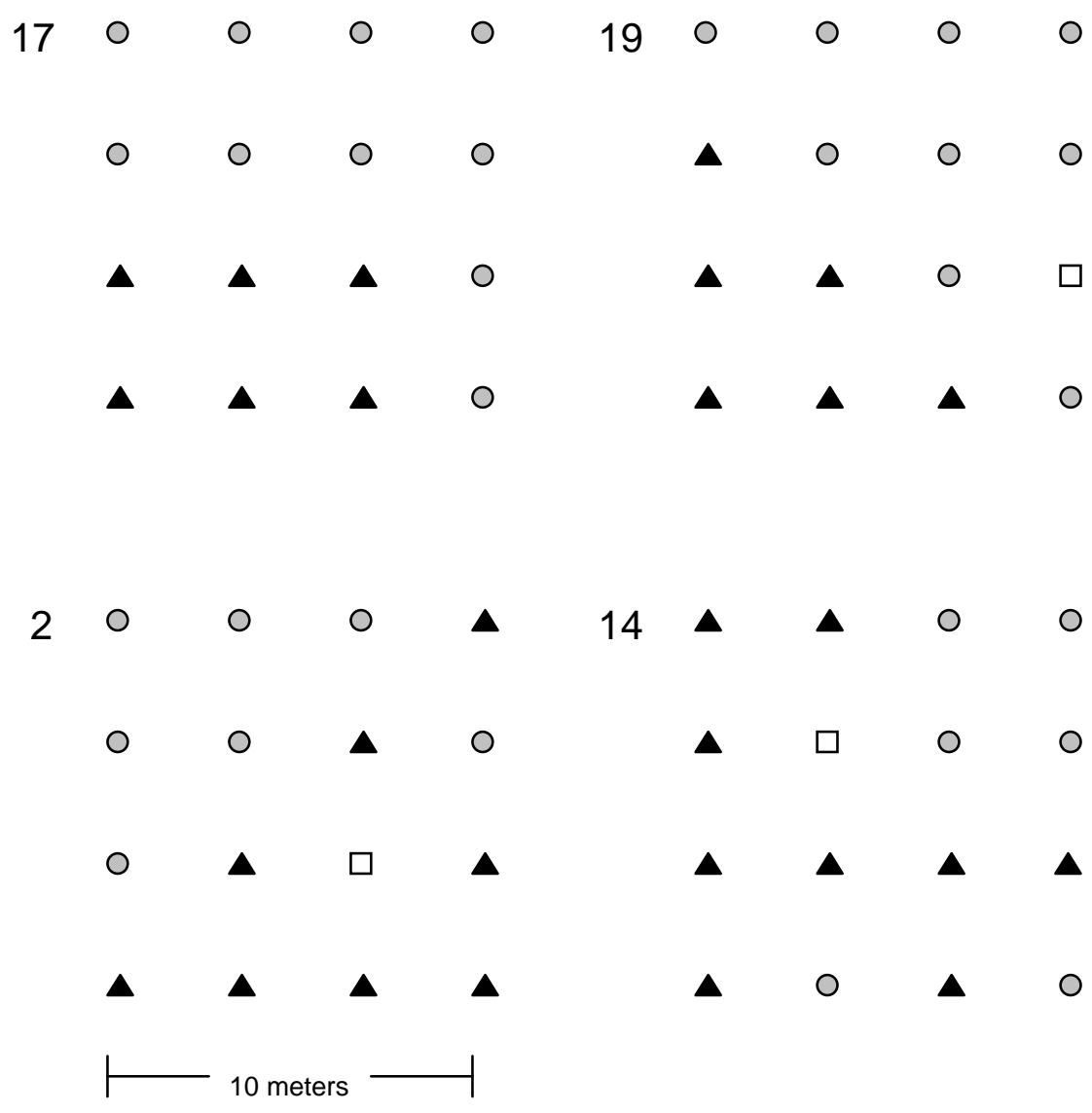

Fig. B1. Diagram of the largely non-overlapping bait capture in the pre-manipulation sample for plots (plot 17, 19, 5, and 14) that had the closest to equal representation of $S$. invicta and $L$. humile. Gray circles are bait stations that L. humile captured; black triangles are bait stations that S. invicta captured; and open squares are bait stations captured by another species. 